\title{
RECUPERAÇÃO DE CÁDMIO DE BATERIAS NÍQUEL-CÁDMIO VIA EXTRAÇÃO SELETIVA COM TRIBUTILFOSFATO (TBP)
}

\author{
Ana Paula Mauro Gonçalves Barandas, Ivam Macedo Valverde Jr. e Júlio Carlos Afonso* \\ Departamento de Química Analítica, Instituto de Química, Universidade Federal do Rio de Janeiro, CP 68563, \\ 21949-900 Rio de Janeiro - RJ, Brasil \\ José Luiz Mantovano e José Waldemar Silva Dias da Cunha \\ Divisão de Química e Materiais Nucleares, Instituto de Engenharia Nuclear, CP 68550, 21945-970 Rio de Janeiro - RJ, Brasil
}

Recebido em 3/1/06; aceito em 4/8/06; publicado na web em 26/3/07

\begin{abstract}
RECOVERY OF CADMIUM FROM NICKEL-CADMIUM BATTERIES VIA SELECTIVE EXTRACTION WITH TRIBUTYLPHOSPHATE (TBP). This work describes a recovery process of cadmium from spent nickel-cadmium batteries by a new hydrometallurgical route based on the selective extraction in hydrochloric acid medium with tributylphosphate (TBP), alone or dissolved in kerosene. The best results were obtained when TBP concentration was at least 75 vol\%. Nickel extraction was negligible under these conditions. It was isolated after processing the rafinate through an anionic ion-exchange column. Final wastes generated are basically sodium chloride solutions, with no turbidity, color or heavy metals present in significant amounts.
\end{abstract}

Keywords: cadmium; TBP; Ni-Cd batteries.

\section{INTRODUÇÃO}

A bateria níquel-cádmio (Ni-Cd) é um exemplo clássico das chamadas baterias recarregáveis. É uma tecnologia antiga, sendo proposta em 1899 pelo sueco W. Jungner (1869-1924) $)^{1,2}$. Ela tem baixo custo, é robusta (vida útil bastante longa), embora seja susceptível ao efeito memória, e divide-se basicamente em dois tipos distintos: a portátil (selada) e a para aplicações industriais e propulsão (não selada). Seu anodo é constituído por cádmio metálico, que se transforma em hidróxido de cádmio, e o catodo é de $\mathrm{NiO}(\mathrm{OH})$, que é convertido em hidróxido de níquel. O eletrólito é uma mistura de hidróxidos de potássio e de sódio. A reação total da bateria é3:

$2 \mathrm{NiO}(\mathrm{OH})+\mathrm{Cd}+\mathrm{H}_{2} \mathrm{O} \underset{\text { carga }}{\stackrel{\text { descarga }}{\text { carga }}} 2 \mathrm{Ni}(\mathrm{OH})_{2}+\mathrm{Cd}(\mathrm{OH})_{2}$

Nessa bateria já foram identificados os seguintes elementos: alumínio, cobalto, carbono, cromo, ferro, manganês e zinco ${ }^{4}$. O grafite e o óxido de ferro(III) aumentam a condutividade elétrica dos hidróxidos de níquel/cádmio ${ }^{5,6}$. O cobalto tem a finalidade de recobrir as partículas de hidróxido de níquel, aumentando a diferença de potencial entre a reação desejada de oxidação do hidróxido e a reação indesejável de descarga de gás oxigênio no eletrodo negativo ${ }^{5}$ :

$4 \mathrm{OH}^{-} \longrightarrow 2 \mathrm{H}_{2} \mathrm{O}+\mathrm{O}_{2}+4 \mathrm{e}^{-}$

O separador, normalmente feito de poliamida, polietileno ou polipropileno ${ }^{7}$, evita o contato direto anodo-catodo com conseqüente curto-circuito e inutilização da bateria.

O mercado mundial de baterias recarregáveis vem crescendo em média $15 \%$ ao ano ${ }^{8,9}$. São também notáveis o valor do mercado global e a previsão de crescimento: de 17,8 bilhões de dólares em 2006 para 23 bilhões em 2010. No Brasil existem mais de 80 milhões de baterias de celular atualmente em uso ${ }^{9}$.

A bateria níquel-cádmio constitui importante foco de preocupação para os ambientalistas. Isso decorre de dois fatores fundamen-

*e-mail: julio@iq.ufrj.br tais: o crescente volume de dispositivos eletroeletrônicos portáteis comercializados anualmente (cerca de $80 \%$ das baterias são embutidas nesses equipamentos), dos quais grande porcentagem vai para o lixo domiciliar após o final da vida útil e, os impactos gerados pelos materiais usados na manufatura dessa bateria, principalmente por causa da persistência ambiental, deposição e concentração em sedimentos, lixos e a bioacumulação do cádmio e do níquel em animais e vegetais ${ }^{10}$. Recentemente, outros modelos recarregáveis portáteis foram desenvolvidos ${ }^{11} \mathrm{em}$ substituição às baterias níquelcádmio, em especial as de níquel metal-hidreto (Ni-MH) e de íonlítio. A área industrial considera que há grande dificuldade para a substituição integral da bateria níquel-cádmio nesse segmento, no estágio atual do conhecimento. Os fabricantes europeus de pilhas e baterias questionam a preocupação com a destinação final desses produtos em geral, com base nos seguintes argumentos ${ }^{12,13}$ : as baterias são responsáveis por menos de $0,001 \%$ em massa do lixo urbano e, apesar de testes extensivos, nunca houve evidência de que baterias e pilhas acarretassem impactos ambientais, inclusive através do descarte em aterros ou de incineração.

No Brasil, por meio da resolução $n^{\circ} 257$ do Conselho Nacional de Meio Ambiente (CONAMA) ${ }^{14}$, as baterias níquel-cádmio devem ser coletadas e remetidas aos fabricantes para uma destinação final segura. Porém, existem alguns problemas relacionados aos mecanismos de coleta de pilhas e baterias no país ${ }^{10}$ : apenas cerca de $11 \%$ do volume produzido é recolhido, exceto para baterias automotivas, que chega a 98\%; falta divulgação de orientação para consumidores e estabelecimentos de que há acordo com postos de venda para receber qualquer tipo de pilha e bateria; não há informações claras sobre a infra-estrutura para reciclagem, nem de projetos de incentivo para o desenvolvimento de tecnologias e, não há dados de avaliação de desempenho do modelo de gestão de pilhas e baterias. Estima-se que, anualmente, $11 \mathrm{t}$ de baterias de celulares sejam descartadas no lixo comum no Brasil ${ }^{9}$. Isso cria um problema ainda longe de uma solução satisfatória para o meio ambiente: uma grande parcela da população não tem consciência de que pilhas e baterias são lixo químico, que podem causar danos à saúde, e que devem ter uma destinação final diferenciada do lixo comum ${ }^{15}$. Nos Estados Unidos 
as baterias níquel-cádmio (e chumbo-ácido) não devem em hipótese alguma ser descartadas com o lixo doméstico, sendo este procedimento regulamentado pelo RCRA ("Resource Conservation and Recovery Act"), pois são consideradas resíduo perigoso, em virtude da toxicidade dos metais e da corrosividade do eletrólito emprega$\mathrm{do}^{16}$. Qualquer alternativa passa pela coleta seletiva e pelo incentivo à pesquisa e ao desenvolvimento de técnicas de tratamento, de reciclagem e de descarte seguro destes materiais ${ }^{15}$.

Os processos de reciclagem de baterias níquel-cádmio propostos seguem três linhas distintas: a baseada em operações de tratamento de minérios, a hidrometalúrgica e a pirometalúrgica. Elas são muitas vezes processadas separadamente das outras devido a dois fatores: a presença do cádmio, que promove algumas dificuldades na recuperação do mercúrio e do zinco por destilação e, a dificuldade de separar o ferro do níquel ${ }^{17}$. Os processos adotados em escala comercial são baseados na rota pirometalúrgica de destilação do cádmio, realizada em circuito fechado, para não haver a liberação de fumos de cádmio ou de seu óxido para o ambiente. Os materiais produzidos são: cádmio, com pureza superior a 99,95\% $\mathrm{m} / \mathrm{m}$, níquel e ferro, utilizados na fabricação de aço inoxidável. Os processos comerciais foram basicamente desenvolvidos por empresas, havendo pouco estudo em termos de aspectos fundamentais $^{18,19}$. O alto custo energético e a elevada insalubridade dos processos pirometalúrgicos vêm incentivando o estudo de alternativas. Além disso, eles não têm versatilidade ${ }^{3}$ quando o desafio é processar materiais multicomponentes.

Recentemente vêm sendo desenvolvidas técnicas de separação de metais de baterias usadas através de rotas hidrometalúrgicas, em uma clara tentativa de obter processos mais viáveis economicamente. A abertura ácida é o meio universal de tratamento por essa via porque a grande maioria das etapas posteriores de fracionamento, independente da natureza, emprega meio ácido. Os processos hidrometalúrgicos, apesar da corrosividade da maioria deles, permitem uma separação fracionada de componentes, reduzem custos energéticos e aceitam escala comercial menor ${ }^{3}$.

Nos trabalhos publicados, existe uma clara preferência pelo emprego de ácido sulfúrico ${ }^{3,17,20-28}$. Uma vez feita a abertura, a solução pode ser processada para recuperar os elementos de duas formas: por extração com solventes ou por métodos eletroquímicos. No primeiro caso, o cádmio pode ser separado mediante o emprego de solventes organofosforados puros ou diluídos em solvente inerte (querosene). Os rendimentos em recuperação são muito elevados (acima de $99 \%$ $\mathrm{m} / \mathrm{m})^{24-28}$. Alguns desses estudos demonstram que o cádmio pode ser isolado de soluções que contenham cobalto, normalmente um elemento-traço das baterias. Não é recomendável tratar as baterias níquel-cádmio e níquel metal-hidreto juntas (teores diferentes de níquel, cádmio e outros elementos caso a caso) para não comprometer a eficiência do processo aplicado à recuperação dos mesmos ${ }^{22,29}$. Outra rota proposta prevê a recuperação do níquel ${ }^{21} \mathrm{e}$ do cádmio ${ }^{17}$ por via eletrolítica similar ao processo de galvanoplastia. Ainda merece menção a proposta de um processo bio-hidrometalúrgico ${ }^{20}$ com bactérias do gênero Thiobacillus. Elas produzem ácido sulfúrico que lixivia os metais dos resíduos, com menor consumo energético e condições menos agressivas de operação. Recentemente empregou-se também ácido clorídrico ${ }^{30}$, com base na elevada solubilidade dos cloretos dos elementos constituintes das baterias em água. Foi possível a extração seqüencial de níquel, cádmio e cobalto com solventes organofosforados sob condições otimizadas ( $\mathrm{pH}$, número de estágios, razão fase aquosa/fase orgânica, concentração do solvente em querosene). A extração do cádmio em meio ácido (sulfúrico ou clorídrico) foi relatada na literatura há bastante tempo ${ }^{23}$.

Este trabalho propõe uma nova rota hidrometalúrgica de processamento de baterias níquel-cádmio usadas em meio de ácido clorídrico. O solvente orgânico utilizado para extração do cádmio foi o tributilfosfato (TBP), citado na literatura como adequado para separação do elemento, porém o meio de trabalho é em ácido sulfúrico ${ }^{24,28,29}$. A escolha do solvente acima visou avaliar seu desempenho em meio clorídrico. A partir do rafinado, avaliou-se a possibilidade de isolamento do níquel. Fez-se também um controle dos resíduos produzidos a fim de adequar a rota de processamento às normas ambientais vigentes, assunto normalmente não abordado na literatura.

\section{PARTE EXPERIMENTAL}

\section{Baterias}

Empregaram-se 300 baterias de níquel-cádmio de telefone celular e de telefone sem fio de 7 fornecedores diferentes, fabricadas entre 2000 e 2001, e com vida útil média de 28 meses (o que concorda com a faixa normalmente citada na literatura, 24-36 meses ${ }^{22,29}$ ). Todas elas foram desmontadas manualmente, removendo-se inicialmente os invólucros externos de plástico, abrindo-se a seguir a blindagem de aço (geralmente de formato cilíndrico), expondo os elementos internos, a saber: o catodo e o anodo; a pasta eletrolítica, de caráter fortemente alcalino, contendo íons $\mathrm{Na}^{+}$e $\mathrm{K}^{+}$(hidróxidos de sódio e potássio); um separador anodo-catodo, feito de material polimérico (poliamida), e uma tela metálica de níquel. Todos os componentes das baterias foram pesados em balança analítica. Os elementos internos foram levados ao processo de dissolução.

\section{Processo de dissolução}

$\mathrm{Na}$ abertura empregou-se ácido clorídrico concentrado (12 mol $\mathrm{L}^{-1}$ ), grau analítico, sem purificação. Os experimentos foram conduzidos sob agitação manual, em capela sob exaustão. Os parâmetros operacionais estabelecidos foram: temperatura de $40{ }^{\circ} \mathrm{C}$; razão mássica (pasta eletrolítica + catodo + anodo + separador polimérico + tela metálica)/ácido clorídrico, $150 \mathrm{~g} \mathrm{~L}^{-1}$.

\section{Extração de cádmio}

A acidez livre foi determinada por titulação de neutralização direta $^{31}$ com hidróxido de sódio $\left(1 \mathrm{~mol} \mathrm{~L}^{-1}\right)$, empregando um peagâmetro digital (eletrodo de referência $\mathrm{Ag} / \mathrm{AgCl})^{2}$.

$\mathrm{O}$ solvente TBP foi utilizado sem nenhuma purificação suplementar, puro ou diluído em querosene desodorizado (25-50-75\% em volume). A extração foi realizada em funil de separação empregando uma razão fase aquosa/fase orgânica (FA/FO) igual a 1 (vol./ vol.). O tempo de extração foi de 3 min, sob agitação manual. Uma segunda extração no rafinado foi efetuada sob a mesma razão volumétrica. Cada procedimento global de extração foi executado em triplicata.

A reextração do cádmio para a fase aquosa foi feita mediante o emprego de solução $6 \mathrm{~mol} \mathrm{~L}^{-1}$ de ácido clorídrico em um único estágio. O metal precipitou após neutralização dessa solução com hidróxido de sódio $12,5 \mathrm{~mol} \mathrm{~L}{ }^{-1}$.

\section{Isolamento do níquel}

Parte do rafinado foi diretamente tratada com hidróxido de sódio $6 \mathrm{~mol} \mathrm{~L}^{-1}$ até $\mathrm{pH}$ em torno de 8 para a precipitação do níquel e demais elementos presentes. Em outra série de experimentos, a acidez livre do rafinado foi ajustada a $7 \mathrm{~mol} \mathrm{~L}^{-1}$ por adição do ácido 12 $\mathrm{mol} \mathrm{L} \mathrm{L}^{-1}$. A seguir, a solução foi eluída $\left(3 \mathrm{~mL} \mathrm{~min}^{-1}\right)$ em coluna (200 x $15 \mathrm{~mm}$ ) preenchida com resina aniônica (Dowex 1) ) $^{32}$, previamente condicionada com ácido clorídrico $7 \mathrm{~mol} \mathrm{~L}^{-1}$. O eluato, de colora- 
Tabela 1. Composição aproximada $(\% \mathrm{~m} / \mathrm{m})$ das baterias níquel-cádmio estudadas*

\begin{tabular}{lcccc}
\hline Marca & Tipo & $\begin{array}{c}\text { invólucro } \\
\text { plástico }\end{array}$ & $\begin{array}{c}\text { blindagem } \\
\text { de aço }\end{array}$ & $\begin{array}{c}\text { catodo + anodo + pasta eletrolítica } \\
+ \text { separador + tela de níquel }\end{array}$ \\
\hline A & Telefone sem fio & $8,0 \pm 0,2$ & $36,1 \pm 0,9$ & $55,9 \pm 0,9$ \\
B & Telefone sem fio & $7,7 \pm 0,2$ & $39,5 \pm 0,9$ & $52,8 \pm 1,0$ \\
C & Telefone sem fio & $8,8 \pm 0,4$ & $38,2 \pm 0,8$ & $53,0 \pm 0,7$ \\
D & Telefone sem fio & $6,9 \pm 0,3$ & $40,1 \pm 0,5$ & $53,0 \pm 0,5$ \\
E & Telefone sem fio & $8,0 \pm 0,1$ & $37,5 \pm 0,6$ & $54,5 \pm 0,9$ \\
F & Telefone sem fio & $6,9 \pm 0,1$ & $37,0 \pm 0,7$ & $56,1 \pm 0,5$ \\
F & Telefone celular & $15,2 \pm 0,4$ & $41,8 \pm 0,4$ & $42,8 \pm 0,8$ \\
G & Telefone celular & $18,9 \pm 0,5$ & $40,9 \pm 0,2$ & $40,2 \pm 0,8$ \\
H & Telefone sem fio & $7,2 \pm 0,2$ & $39,6 \pm 0,5$ & $53,2 \pm 1,0$ \\
\hline
\end{tabular}

* valores expressos em intervalo de confiança a $95 \%$

ção verde, foi tratado com hidróxido de sódio $12,5 \mathrm{~mol} \mathrm{~L}^{-1}$ até $\mathrm{pH}$ em torno de 10. Após o isolamento do precipitado, a solução foi tratada com ácido clorídrico $12 \mathrm{~mol} \mathrm{~L}^{-1}$ para levar o $\mathrm{pH}$ a 7 , gerando um novo precipitado, que foi separado por filtração.

A dosagem dos metais foi feita por fluorescência de raios-X (FRX). O aparelho utilizado foi o S4 - Explorer - Bruker - AXS (tubo $1 \mathrm{KeV}$ de ródio). Curvas de calibração foram estabelecidas e as concentrações das soluções-padrão variaram de 0,1 a $10 \mathrm{~g} \mathrm{~L}^{-1}$. Todas as amostras foram introduzidas em papéis de filtro de mesmo diâmetro $(3,8 \mathrm{~cm})$ por meio de pipetas calibradas utilizando-se sempre o mesmo volume de amostra $(200 \mu \mathrm{L})$.

\section{RESULTADOS E DISCUSSÃO}

\section{Composição média das baterias}

A Tabela 1 mostra os dados de percentual em massa de todos os componentes (invólucro de plástico, blindagem e elementos internos). As variações são pouco significativas para cada tipo de bateria utilizado (telefone sem fio/celular), o que concorda com estudos prévios da literatura $^{29}$. A composição para as baterias de telefones sem fio é bem próxima àquelas já relatadas ${ }^{17,21}$. O percentual em massa do invólucro externo $(<8 \% \mathrm{~m} / \mathrm{m})$ de material plástico de baterias de telefones sem fio é menor que no caso dos modelos para telefonia celular $(>15 \% \mathrm{~m} /$ $\mathrm{m})$, que são mais pesadas, sendo essa diferença compensada pelo menor percentual dos elementos internos da bateria.

\section{Processo de dissolução}

Com base nos protocolos experimentais mostrados anteriormente, foi possível obter a solubilização de todos os componentes internos, exceto o separador (que foi isolado). O tempo de dissolução foi de cerca de $30 \mathrm{~min}$, com exceção da tela metálica que, para solubilização completa, foram necessárias cerca de 12 h, obtendo-se uma solução de intensa coloração verde devida ao íon $\mathrm{Ni}^{2+}$ presente.

\section{Elementos presentes}

A Tabela 2 apresenta os teores medidos de níquel e cádmio nas amostras estudadas. Aparentemente, a tendência da atual tecnologia é diminuir a quantidade de níquel presente nos modelos de última geração. Em nenhum caso se chegou ao valor máximo $(32 \% \mathrm{~m} / \mathrm{m})$ encontrado em um levantamento da literatura até o final do século $\mathrm{XX}^{10}$, enquanto que em muitas amostras os valores encontrados se situam abaixo do valor mínimo histórico relatado $(12 \% \mathrm{~m} / \mathrm{m})$.

Apesar da diminuição da quantidade de níquel presente nas baterias, o mesmo não ocorreu com o cádmio. As novas tecnologias pare- cem que ainda não conseguiram diminuir o teor deste metal da mesma forma como no caso do níquel. Pode-se observar na Tabela 2 que a bateria $\mathrm{E}$ apresentou teor de cádmio até maior que o valor médio relatado na literatura ${ }^{10}(16 \% \mathrm{~m} / \mathrm{m})$ e nenhuma amostra ficou abaixo do valor mínimo registrado $(10 \% \mathrm{~m} / \mathrm{m})$ até o ano 2000 .

Tabela 2. Percentual médio $(\mathrm{m} / \mathrm{m})$ de níquel e cádmio nas baterias em estudo em relação ao produto original antes da desmontagem*

\begin{tabular}{llrc}
\hline Marca & \multicolumn{1}{c}{ Tipo } & \multicolumn{1}{c}{ Níquel } & \multicolumn{1}{c}{ Cádmio } \\
\hline A & Telefone sem fio & $12,5 \pm 0,2$ & $12,0 \pm 0,6$ \\
$\mathrm{~B}$ & Telefone sem fio & $7,8 \pm 0,3$ & $12,2 \pm 0,2$ \\
$\mathrm{C}$ & Telefone sem fio & $11,1 \pm 0,4$ & $11,1 \pm 0,2$ \\
$\mathrm{D}$ & Telefone sem fio & $8,5 \pm 0,2$ & $13,4 \pm 0,6$ \\
$\mathrm{E}$ & Telefone sem fio & $10,2 \pm 0,2$ & $18,9 \pm 0,5$ \\
$\mathrm{~F}$ & Telefone sem fio & $6,9 \pm 0,3$ & $14,6 \pm 0,5$ \\
$\mathrm{~F}$ & Telefone celular & $7,5 \pm 0,3$ & $15,5 \pm 0,7$ \\
$\mathrm{G}$ & Telefone celular & $9,0 \pm 0,4$ & $15,5 \pm 0,3$ \\
$\mathrm{H}$ & Telefone sem fio & $13,4 \pm 0,5$ & $13,7 \pm 0,4$ \\
\hline
\end{tabular}

* valores expressos em intervalo de confiança a $95 \%$

Além da presença de níquel e de cádmio, a FRX acusou a existência de outros 9 elementos, cujos teores, expressos em percentuais médios $(\mathrm{m} / \mathrm{m})$ em relação à bateria original, obtidos em intervalo de confiança de $95 \%$, são: alumínio $(0,2 \pm 0,1)$, potássio $(2,5 \pm$ $0,2)$, manganês $(0,2 \pm 0,1)$, ferro $(12,7 \pm 0,6)$, sódio $(1,9 \pm 0,1)$, cromo $(<0,1)$, cálcio $(0,6 \pm 0,1)$, cobalto $(0,9 \pm 0,2)$ e zinco $(<0,1)$. Com exceção do cálcio, os demais elementos já foram mencionados em outros trabalhos ${ }^{22,29}$. Os teores acima são comparáveis àqueles já relatados na literatura ${ }^{22,29}$, exceto no que se refere ao ferro, que é cerca de duas vezes a faixa registrada $(5-6 \% \mathrm{~m} / \mathrm{m})$.

\section{Separação de cádmio do níquel}

A acidez livre média das lixívias obtidas foi de 7,0 $\pm 0,3 \mathrm{~mol} \mathrm{~L}^{-1}$, e as concentrações de $\mathrm{Ni}^{2+}$ e de $\mathrm{Cd}^{2+}$ estavam na faixa $14,5 \pm 1,7 \mathrm{e}$ $23,3 \pm 2,1 \mathrm{~g} \mathrm{~L}^{-1}$, respectivamente. A Tabela 3 apresenta os resultados dos coeficientes de distribuição (D) para cádmio e níquel em função da proporção entre TBP e querosene após as duas extrações realizadas. Para a $2^{\mathrm{a}}$ extração, a acidez livre medida era de 4,6 \pm $0,2 \mathrm{~mol} \mathrm{~L}^{-1}$.

$\mathrm{Na}$ primeira extração houve uma retração média de $14 \%$ do volume da fase aquosa original quando do emprego de TBP puro, percentual esse quase zero quando a concentração do TBP era de $25 \%$ vol. em querosene (as fases separaram-se completamente em 10 min). Após a $1^{\mathrm{a}}$ extração, a concentração do íon $\mathrm{Ni}^{2+}$ na fase 
Tabela 3. Valores dos coeficientes de distribuição (D) calculados para as duas extrações de cádmio em série de uma lixívia com ácido clorídrico de baterias níquel-cádmio com TBP dissolvido em querosene

\begin{tabular}{lcccc}
\hline Metal (1 $1^{\text {a extração) }}$ & TBP $100 \%$ vol. & TBP 75\% vol. & TBP 50\% vol. & TBP 25\% vol. \\
\hline Níquel & $3,5 \times 10^{-3}$ & $3,2 \times 10^{-3}$ & $2,8 \times 10^{-3}$ & $2,1 \times 10^{-3}$ \\
Cádmio & $>10^{5}$ & $1,1 \times 10^{2}$ & $4,1 \times 10^{-1}$ & $6,5 \times 10^{-2}$ \\
$\mathrm{D}_{\text {Cádmio }} / \mathrm{D}_{\text {Níquel }}$ & $>2,9 \times 10^{7}$ & $3,4 \times 10^{4}$ & $1,5 \times 10^{2}$ & $3,1 \times 10^{1}$ \\
\hline Metal $\left(2^{\mathrm{a}}\right.$ extração) & TBP $100 \%$ vol. & TBP $75 \%$ vol. & TBP 50\% vol. & TBP 25\% vol. \\
\hline Níquel & $1,3 \times 10^{-2}$ & $1,1 \times 10^{-2}$ & $1,0 \times 10^{-2}$ & $6,0 \times 10^{-3}$ \\
Cádmio & $>10^{5}$ & $1,3 \times 10^{2}$ & $1,0 \times 10^{1}$ & $6,5 \times 10^{-1}$ \\
$\mathrm{D}_{\text {Cádmio }} / \mathrm{D}_{\text {Níquel }}$ & $>7,7 \times 10^{6}$ & $1,2 \times 10^{4}$ & $1,0 \times 10^{3}$ & $1,1 \times 10^{2}$ \\
\hline
\end{tabular}

aquosa era de $16,1 \pm 0,9 \mathrm{~g} \mathrm{~L}^{-1}$, enquanto a do íon $\mathrm{Cd}^{2+}$ variou em função da concentração de TBP: de $1,9 \pm 0,8 \mathrm{~g} \mathrm{~L}^{-1}$ (TBP puro) a $25,0 \pm 1,4 \mathrm{~g} \mathrm{~L}^{-1}$ (TBP a $25 \%$ vol.).

A Figura 1 mostra os resultados para a extração do cádmio após os dois procedimentos em série. Deve-se destacar que o íon $\mathrm{Ni}^{2+}$ não foi significativamente extraído nas condições experimentais deste estudo. Outro ponto é a baixa extração do ferro $(<1 \% \mathrm{~m} / \mathrm{m})$, fato relevante, posto que este elemento costuma interferir nos processos de extração de metais divalentes com solventes orgânicos em meio ácido ${ }^{33}$. O cádmio foi quantitativamente extraído $(99,9 \%$ $\mathrm{m} / \mathrm{m}$ ) desde que a concentração do TBP fosse ao menos $75 \%$ vol., já que o desempenho em soluções mais diluídas decresceu notavelmente, especialmente se apenas considerado o $1^{\circ}$ estágio. A pureza do cádmio isolado foi da ordem de $99,5 \% \mathrm{~m} / \mathrm{m}$.

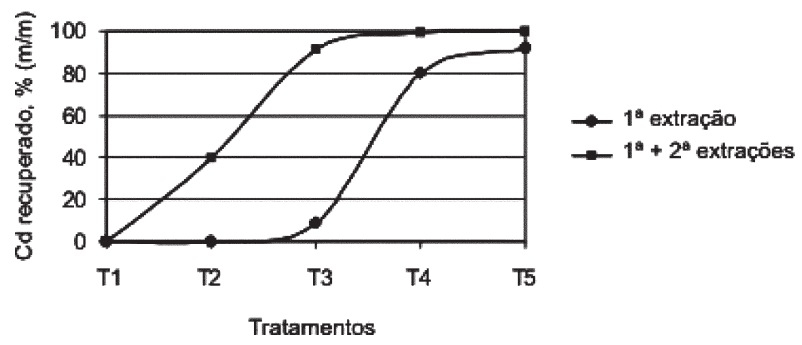

Figura 1. Recuperação $(\% \mathrm{~m} / \mathrm{m})$ de cádmio em função da concentração de TBP em querosene (2 estágios, relação $F A / F O=1$ vol/vol, $25^{\circ} \mathrm{C}$ ), onde: $T 1$ = querosene puro; $T 2=T B P$ a $25 \%$ vol.; T3 = TBP a $50 \%$ vol.; T4 =TBP $a$ $75 \%$ vol.; T5 = TBP puro

\section{Isolamento do níquel}

O precipitado obtido no tratamento direto do rafinado com hidróxido de sódio apresenta, segundo as análises por FRX, níquel, alumínio, manganês, ferro, cromo, cobalto e zinco, resultado esse em conformidade com os dados de caracterização das amostras. O níquel corresponde a cerca de $80 \% \mathrm{~m} / \mathrm{m}$ de todos os metais presentes. $\mathrm{O}$ ferro é o metal contaminante mais abundante (aproximadamente $15 \% \mathrm{~m} / \mathrm{m}$ do total). Uma grande dificuldade prática é a recuperação do níquel por extração com solventes orgânicos na presença dos elementos acima citados. Além de problemas relativos à seletividade desse procedimento, as melhores condições experimentais são obtidas após a neutralização (o pH varia entre 6 e 8,5 conforme o estudo $)^{30,34}$. A neutralização com essa finalidade significa um aumento da geração final de resíduos aquosos e também um consumo adicional de reagentes e água, o que reduz a atratividade econômica do processo ${ }^{34}$. A melhor alternativa seria isolar o níquel diretamente da solução ácida após a remoção do cádmio. O emprego de resinas aniônicas é uma alternativa interessante: com base na estabilidade dos clorocomplexos dos metais da $1^{\text {a }}$ linha de transi- ção ${ }^{35}$, em acidez livre de ácido clorídrico $7 \mathrm{~mol} \mathrm{~L}^{-1}$, o íon $\mathrm{Ni}^{2+}$ (além do $\mathrm{Cr}^{3+}$ e do $\mathrm{Al}^{3+}$ ) não forma complexos aniônicos, ao contrário dos íons $\mathrm{Mn}^{2+}, \mathrm{Fe}^{3+}, \mathrm{Zn}^{2+}$ e $\mathrm{Co}^{2+}$. Isso significa uma rota de obtenção de um produto final de níquel particularmente livre de ferro e cobalto. O tratamento do eluato com hidróxido de sódio até $\mathrm{pH} 10$ permitiu o isolamento do níquel, com alto rendimento $(99,8 \% \mathrm{~m} / \mathrm{m})$ e livre de alumínio e cromo, os quais formam hidroxicomplexos solúveis. De fato, a análise por FRX da massa obtida mostrou que o níquel tinha elevado grau de pureza $(99,5 \% \mathrm{~m} / \mathrm{m})$ : alumínio e cromo correspondiam a menos de $0,2 \% \mathrm{~m} / \mathrm{m}$ do total dos metais nesse precipitado, confirmando as premissas iniciais. Uma vez isolado o níquel, o ajuste do $\mathrm{pH}$ a 7 precipitou o alumínio e o cromo solúveis.

Após a saturação da coluna, a lavagem com água (duas vezes o volume da resina) removeu ferro, cobalto, manganês e zinco adsorvidos, os quais foram precipitados com hidróxido de sódio + carbonato de sódio ${ }^{36}$.

\section{Controle de qualidade do TBP usado}

As soluções de TBP e o solvente puro foram utilizados até quatro vezes sem alteração significativa de eficiência. A partir daí foi realizado um tratamento em um único estágio com hidróxido de sódio $3 \mathrm{~mol} \mathrm{~L}^{-1}$ (remoção de toda a acidez), seguido de lavagem com ácido sulfúrico $1 \mathrm{~mol} \mathrm{~L}^{-1}$ (um estágio) e com água pura até que a fase aquosa apresentasse $\mathrm{pH}$ neutro. A recuperação média do TBP puro foi de $95 \%$ vol., sendo que no caso das soluções em querosene é preciso adicionar TBP (“make up") a fim de restabelecer a concentração original.

\section{Gestão de resíduos}

O processamento de uma bateria usada é complexo face ao fato de ser um produto composto por muitos materiais diferentes em natureza, cuja destinação final é diferente caso a caso. Assim, o separador polimérico e a carcaça externa plástica podem ser recicladas ou então incineradas para recuperação energética (recuperação quaternária) ${ }^{37}$. O invólucro de aço das baterias pode ser reciclado. Os precipitados obtidos após a precipitação do níquel e a lavagem da resina aniônica com água (ver acima) podem ser dispostos em aterros para materiais perigosos (classe I) ou são passíveis de co-processamento, segundo as regras da resolução 264 do CONAMA ${ }^{38}$.

Os resíduos finais aquosos representam o principal desafio de gestão. Eles precisam apresentar as seguintes características: $\mathrm{pH}$ entre 5 e 9, ausência de coloração e turbidez (sólidos em suspensão), caráter redox indiferente e concentração de metais pesados dentro das normas estabelecidas na resolução 357 do CONAMA $^{39}$.

As soluções empregadas no tratamento das soluções de TBP (vide acima) foram misturadas entre si e neutralizadas, com adição de solução de $\mathrm{Ca}^{2+}$, para precipitar o fosfato presente. Nos demais casos, 
Tabela 4. Estimativa de consumo de reagentes e água no processamento de baterias níquel-cádmio usadas (base: $1 \mathrm{t}$ de componentes internos e TBP a $75 \%$ vol. em querosene)

\begin{tabular}{|c|c|c|}
\hline Item & Finalidade & Quantidade \\
\hline \multirow[t]{5}{*}{ Ácido clorídrico $12 \mathrm{~mol} \mathrm{~L}^{-1}$} & Dissolução dos componentes internos da bateria & $6700 \mathrm{~L}$ \\
\hline & Reextração do cádmio para a fase aquosa & $12000 \mathrm{~L}$ \\
\hline & Ajuste da acidez livre $\left(4,6-7 \mathrm{~mol} \mathrm{~L}^{-1}\right)$ & $2880 \mathrm{~L}$ \\
\hline & Condicionamento da resina aniônica & $1000 \mathrm{~L}$ \\
\hline & Neutralização da solução após a precipitação do níquel & $50 \mathrm{~L}$ \\
\hline \multirow{3}{*}{$\begin{array}{l}\text { Hidróxido de sódio } 12,5 \mathrm{~mol} \mathrm{~L}^{-1} \\
\text { (ou } 500 \mathrm{~g} \mathrm{~L}^{-1} \text { ) }\end{array}$} & Precipitação do níquel & $2500 \mathrm{~kg}$ \\
\hline & Precipitação do cádmio & $5800 \mathrm{~kg}$ \\
\hline & Tratamento do TBP usado* & $1520 \mathrm{~kg}$ \\
\hline \multirow[t]{2}{*}{ TBP } & Reposição após tratamento do solvente usado* & $500 \mathrm{~L}$ \\
\hline & Extração do cádmio* & $9500 \mathrm{~L}$ \\
\hline Querosene desodorizado & Diluente do TBP* & $3200 \mathrm{~L}$ \\
\hline Resina Dowex 1 & Retenção de ferro, cobalto, manganês e zinco & $240 \mathrm{~kg}$ \\
\hline Ácido sulfúrico concentrado & Tratamento do TBP usado* & $700 \mathrm{~L}$ \\
\hline \multirow[t]{5}{*}{ Água } & Lavagem dos precipitados contendo níquel e cádmio & ca. $2000 \mathrm{~L}$ \\
\hline & Preparar ácido sulfúrico $1 \mathrm{~mol} \mathrm{~L}^{-1}$ (tratamento do TBP usado) & $12600 \mathrm{~L}$ \\
\hline & Preparar hidróxido de sódio $3 \mathrm{~mol} \mathrm{~L}^{-1}$ (tratamento do TBP usado) & $12670 \mathrm{~L}$ \\
\hline & Preparar ácido clorídrico $7 \mathrm{~mol} \mathrm{~L}^{-1}$ (condicionamento da resina) & $720 \mathrm{~L}$ \\
\hline & Lavagem da coluna (dessorção dos elementos retidos) & $1000 \mathrm{~L}$ \\
\hline
\end{tabular}

* a quantidade apresentada é $1 / 4$ do total porque o TBP e suas soluções são utilizáveis por quatro ciclos de processamento sem necessidade de tratamento da fase orgânica usada.

as soluções finais são próximas da neutralidade. Elas consistem essencialmente de soluções de cloreto de sódio, com menos de 50 ppm de metais pesados (ferro, manganês, níquel e cádmio). Embora sejam soluções incolores, com baixíssimos teores em metais pesados e de caráter redox indiferente, uma questão que se levanta é a altíssima salinidade desses efluentes devido ao emprego de ácido clorídrico concentrado na abertura e na reextração do cádmio.

A descrição acima é diferente dos estudos realizados com ácido clorídrico recentemente publicados ${ }^{30}$. Nesse caso, empregou-se ácido diluído ( $\mathrm{pH}$ 1,5) e as reextrações do cádmio foram realizadas em três estágios com relação FA/FO 1,75:1 (vol/vol), usando-se água pura. Isso significa uma condição operacional menos agressiva, mas leva à geração de um enorme volume final de resíduos aquosos. Os estudos com ácido sulfúrico também geralmente empregam o ácido diluído $\left(0,5-4,0 \mathrm{~mol} \mathrm{~L}^{-1}\right)^{3,17,21,23}$ e razões mássicas bateria/solução ácida entre 10 e $100 \mathrm{~g} \mathrm{~L}^{-1}$. Neste trabalho a razão usada foi $150 \mathrm{~g} \mathrm{~L}^{-1}$, ou seja, de 1,5 a 15 vezes mais, por conta do emprego de ácido concentrado. Por isso o volume de resíduo aquoso gerado $\left(10 \mathrm{~mL} \mathrm{~g}^{-1}\right.$ de componente interno processado) foi cerca de dez vezes inferior ao da literatura. $\mathrm{O}$ binômio concentração de sal e volume de efluente final deve ponderado em vista de aspectos da legislação ambiental vigente, da eventual utilização dessa salmoura em algum processo e do custo local da água tratada. Uma solução ácida mais concentrada é mais corrosiva, exigindo material mais caro, mas reduz o volume de operação ou para o mesmo volume mais material pode ser processado (aumento de escala). Uma solução de lixívia mais diluída é menos corrosiva, mas exige maiores volumes de equipamento e uma escala de trabalho mais reduzida.

A Tabela 4 ilustra uma estimativa do consumo de insumos e água do processo apresentado neste trabalho, tendo por base o tratamento de $1 \mathrm{t}$ de componentes internos das baterias níquel-cádmio (estabeleceu-se o trabalho com TBP a 75\% vol. em querosene). Com base nas concentrações médias de níquel e cádmio após a dissolução dos componentes internos, de $1 \mathrm{t}$ de material processado obtém-se $123,1 \mathrm{~kg}$ de óxido de níquel $(99,5 \% \mathrm{~m} / \mathrm{m}$ de pureza), e $177,5 \mathrm{~kg}$ de óxido de cádmio $(99,5 \% \mathrm{~m} / \mathrm{m}$ de pureza).

Existe uma forte concentração no consumo de ácido clorídrico e do hidróxido de sódio porque esses reagentes são empregados em diversas etapas. $\mathrm{O}$ custo do solvente TBP é amortizado devido à possibilidade de quatro empregos sucessivos. O custo da resina também é amortizado pelo processo de regeneração da coluna.

\section{CONCLUSÕES}

O Cd pode ser recuperado com elevado rendimento $(99,9 \%$ $\mathrm{m} / \mathrm{m})$, alto grau de pureza $(99,5 \% \mathrm{~m} / \mathrm{m})$ e livre de níquel e ferro, por meio de extração com TBP puro ou levemente diluído em querosene. Nas condições deste trabalho, a geração de resíduos finais aquosos é dez vezes menor frente aos estudos publicados na literatura. De cada t de material processado pode obter-se $177,5 \mathrm{~kg}$ de cádmio como óxido. Os dados desta pesquisa apontam para a aplicabilidade de resinas aniônicas no isolamento do níquel, com alto rendimento $(99,8 \% \mathrm{~m} / \mathrm{m})$ e pureza $(99,5 \% \mathrm{~m} / \mathrm{m})$ a partir do rafinado (sem cádmio), bastando para isso o ajuste da acidez livre. Esse procedimento elimina a interferência de elementos como ferro e cobalto. De cada tonelada de material processado recupera-se $123,1 \mathrm{~kg}$ de níquel na forma de óxido.

\section{AGRADECIMENTOS}

À Divisão de Química e Materiais Nucleares do Instituto de Engenharia Nuclear pelas análises químicas necessárias a este trabalho. A. P. M. G. Barandas agradece à Fundação de Amparo à Pesquisa do Estado do Rio de Janeiro (FAPERJ) e à CAPES pela bolsa de M.Sc; I. M. Valverde Jr. agradece à Agência Nacional de Petróleo (ANP) a concessão de bolsa de M. Sc. Ao CNPq pelo auxílio financeiro.

\section{REFERÊNCIAS}

1. http://www.cadex.com/download/NA_Battery History.pdf, acessada em Outubro 2005.

2. Espinosa, D. C. R.; Tenório, J. A. S.; J. Power Sources 2006, 157, 600.

3. Nogueira, C. A.; Margarido, F.; Hydrometallurgy 2004, 72, 111.

4. Rydh, C. J.; Svard, B.; Sci. Total Environ. 2003, 302, 167.

5. http://www.rbrc.org/call2recycle/licensee/index.html, acessada em Junho 2006. 
6. Grant, J. C.; Application Engineering Handbook, General Electric Company: Washington, 2004, p. 2-1 - 2-14.

7. Besenhard, J. O.; Handbook of Battery Materials, Wilet-WCH: Nova Iorque, 1999.

8. http://www.epba-europe.org/docs/tech01.htm, acessada em Abril 2005.

9. http://shs.cemol.com.br/noticiacomentada/020503_not01.asp, acessada em Junho 2005.

10. Furtado, J. S.; Baterias Esgotadas: Legislações \& Gestão, Relatório elaborado para o Ministério do Meio Ambiente, São Paulo, Brasil, 2003.

11. http://www.ambientebrasil.com.br/composer.php3 ?base=residuos/ index.php3\&conteudo=./residuos/pilhas.html, acessada em Julho 2005.

12. Impact Assessment on Selected Policy Options for Revision of the Battery Directive, European Comission, Directorate General Environment, relatório final, Julho 2003

13. http://www.bbma.co.uk/environment.htm, acessada em Setembro 2005.

14. Resolução No 257do Conselho Nacional de Meio Ambiente (CONAMA), de 30/06/1999, Diário Oficial da União, 22/07/1999.

15. Reidler, N. M. V. L.; Dissertação de Mestrado, Universidade de São Paulo, Brasil, 2002.

16. www.p2pays.org/ref/07/06033.htm, acessada em Novembro 2005.

17. Freitas, M. B. J. G.; Rosalém, S. F.; J. Power Sources 2005, 139, 366.

18. Espinosa, D. C. R.; Tenório, J. A. S.; J. Power Sources 2004, 135, 320

19. Espinosa, D. C. R.; Tenório, J. A. S.; J. Power Sources 2004, 136, 186

20. Zhu, N.; Zhang, L.; Li, C.; Cai, C.; Waste Management 2003, 23, 703.

21. Rozário, A.; Silva, R. K. S.; Freitas, M. B. J. G.; J. Power Sources, no prelo.

22. Matuano, D. P.; Dorella, G.; Elias, R. C. A.; Mansur, M. B.; J. Power Sources 2006, 159, 1510.
23. Tait, B. K.; Hydrometallurgy 1993, 32, 365.

24. Galán, B.; Chem. Eng. J. 1998, 70, 237.

25. Nogueira, C. A.; Delmas, F.; Hydrometallurgy 1999, 52, 267

26. Rickelton, W. A.; Hydrometallurgy 1998, 50, 339.

27. Preston, J. S.; Patrick, J. H.; Steinbach, G.; Hydrometallurgy 1994, 36, 143.

28. Owusu, G.; Hydrometallurgy 1998, 47, 205.

29. Mantuano, D. P.; Dissertação de Mestrado, Universidade Federal de Minas Gerais, Brasil, 2005.

30. Reddy, B. R.; Priya, D. N.; Rao, S. V.; Radhika, P.; Hydrometallurgy 2005, 77, 253.

31. Vogel, A. I.; Análise Química Quantitativa, 5 ed., Livros Técnicos e Científicos: Rio de Janeiro, 1992.

32. Charles, S.; Dubois, F.; Yunus, S.; Doncket, E. V.; J. Fluorescence 2000, 10, 99.

33. Souza, R. M. P.; Leão, V. A.; Pina, P. S.; Rev. Esc. Minas 2005, 58, 375.

34. John, L. W.; Prefeasibility Process Flowsheets for Cobalt Recovery, Biometallurgical: Gympie, 1999.

35. Kraus, K. A.; Moore, G. E.; J. Am. Chem. Soc. 1953, 75, 1460.

36. Afonso, J. C.; Noronha, L. A.; Felipe, R. P.; Freidinger, N.; Quim. Nova 2003, 26, 602 .

37. Mano, E. B.; Bonelli, C. M. C.; Rev. Quim. Industrial 1994, 698, 18.

38. Resolução No 264 do Conselho Nacional de Meio Ambiente (CONAMA), de 26/08/1999, Diário Oficial da União, 20/03/2000.

39. Resolução № 357 do Conselho Nacional de Meio Ambiente (CONAMA), de 18/03/2005, Diário Oficial da União, 19/03/2005. 